\section{Collaboration and learning}

Sergio A. Dib'
I n December 2014, I completed a four-year period as the editor-in-chief of the Brazilian Archives of Endocrinology and Metabolism (ABE\&M). I was honored and satisfied for having completed this period with the collaboration of such hardworking associated editors. I thank each one of them for their patience, for the time they dedicated to the journal, their integrity, and their critical analysis and didactics in the interface between authors and reviewers, during the flow of the manuscripts submitted to publication in the ABE\&M. Similarly, I thank all the editorial body and the reviewers, who are the pillars for the agility and rapidity between the submission and publication of the article, always with the logistic support of our editorial assistance secretary.

Rigor and care in the evaluation of the manuscripts are determinant factors in the performance by citations, in the relevance of the studies published, and in the quality of the articles. In this sense, it is also important that not only issues are regular (we kept the journal with nine issues per year), but also the number of articles per year (greater than 80). In order to regulate the publishing procedures in ABE\&M after publication, the publishing authorization and copyright cession term, a tool for the transference of the copyright to ABE\&M, was created with the aid of the Juridical Department of the Brazilian Society of Endocrinology and Metabolism.

In this era when publications became profuse and sophisticated, there is an increase in the prevalence of plagiarism, including in journals of high impact factor. In order to protect $A B E \& M$ from plagiarism, an anti-plagiarism tool was recently acquired by us, and all manuscripts will be analyzed by it before being published.

In the period of our administration, conversion and marking in XML of articles in their final layout was instituted in SciELO (Scientific Electronic Library Online), which was a requirement for PubMed indexation, and we also migrated ABE\&M to the Scholar One site in order to make submission and publishing procedures faster for authors, co-editors and reviewers.

In order to make ABE\&M articles adequate for both academic readers and clinical endocrinologists, we made an effort to regularly publish clinical articles and supplements with specific topics of interest for clinical and endocrinology practice, such as thyroid diseases, female endocrinology, and metabolic bone diseases.

As for learning, I recycled my knowledge as I reviewed a large number of studies in different areas of endocrinology before sending it to the co-editors. In parallel, in meetings organized by SciELO, Fapesp, CNPq, Bireme, and FapUnifesp, in which editors of international and Brazilian journals took part, I learned a lot on the editorial coordination of a scientific journal and on the optimization of visibility, credibility, and scientometric measurements. Among the interesting articles received by the journal, one called my particular attention: an experience shared by prof. Carlos F. M. Menck,
${ }^{1}$ Associated full professor. Endocrinology Chair - Department of Medicine, Escola Paulista de Medicina, Universidade Federal de São Paulo (Unifesp) EPM), São Paulo, SP, Brazil

Correspondence to: Sergio A. Dib

Rua Botucatu, 572 - cj. 83 04023-062 - São Paulo, SP, Brazil

Received on Jan/30/2015 Accepted on Jan/30/2015

DOI: 10.1590/2359-3997000000001 
editor-in-chief and his editorial team of Genetics and Molecular Biology (GMB), as it corresponds to topics that are many times discussed in meeting with co-editors to improve international placement of $\mathrm{ABE} \& \mathrm{M}$ and its impact factor. In summary, the main issues pointed out by prof. Menck were: (1) Changing the name of the Brazilian Journal of Genetics to Genetics and Molecular Biology; (2) publication in English since the first issue; (3) Rigorous evaluation of the manuscripts; (4) Marking of the full text in XML; (5) Increasing the number of published studies that have authors of international affiliations; (6) Reducing the processing time for manuscripts, with a median of 4 months. I would add two other items to this list: (7) Attention and optimization in the citation of articles published in ABE\&M, when possible, in articles of Brazilian authors published in other Brazilian and International journals; and (8) Professional financial management. I consider that $\mathrm{ABE} \& \mathrm{M}$ is in the right moment to continue the discussion and implementation of these changes.

Finally, I would like to thank the presidents of the Brazilian Society of Endocrinology, dr. Airton Golbert and dr. Nina Musolino for their support during my administration of ABE\&M. I wish the next editor-inchief, prof. Marcello Bronstein and his co-editors a period of huge achievements in the command of the new Archives of Endocrinology and Metabolism. 